\title{
POTENCIALIDADE DO NDVI PARA MAPEAMENTO DO ESTADO DE CONSERVAÇÃO EM APP NAS BH DOS RIOS BUTUÍ E ICAMAQUÃ
}

\author{
Anderson Luiz Godinho Belem ${ }^{\text {(a) }}$, Raquel Mendes Rodrigues ${ }^{(b)}$ \\ (a) Docente, Instituto Federal Farroupilha, andebelem@ gmail.com \\ (b) Discente Geografia, Universidade Federal do Paraná, raquel.mr.rodrigues@ gmail.com
}

\section{EIXO: BACIAS HIDROGRÁFICAS E RECURSOS HÍDRICOS: ANÁLISE, PLANEJAMENTO E GESTÃO}

\begin{abstract}
Resumo
O Índice de Vegetação da Diferença Normalizada (NDVI) é uma relevante ferramenta para compreender a distribuição e a maturidade da vegetação de modo geral. Porém, no contexto agropecuário pode gerar um produto capaz de analisar dentre outras coisas, o respeito às áreas de preservação permanentes (APP). Este trabalho busca compreender o estado de conservação de APPs nas bacias hidrográficas do rio Butuí e do rio Iquamaquã, afluentes diretos do rio Uruguai, ambas localizadas no oeste do Rio Grande do Sul. Para realização do trabalho foi utilizada imagem LANDSAT/TM8, do verão de 2017, o processamento ocorreu no software QGIS2.12 gerando um NDVI da área. A pesquisa, em fase inicial, mostra o respeito às APPs em cursos da água maiores, enquanto que nos afluentes de menor ordem há maiores impactos e desrespeito à legislação. Concluíse que o NDVI é uma ferramenta válida para o procedimento sendo necessários ajustes voltados a identificação da vegetação nativa.
\end{abstract}

Palavras chave: Conservação em APP; rio Uruguai; Fronteira Oeste.

\section{Introdução}

O Brasil está vivenciando nos ultimos anos uma constante pressão sobre o seu capital natural. Pode-se verificar tal momento histórico a partir de mudanças constantes e por vezes intensas na legislação ambiental, como no caso do código florestal e nas constantes prorrogações nos prazos para a implementação de suas novas regras, como o Cadastro Ambiental Rural. Outras evidências são a questão da expansão da fronteira agrícola cada vez mais interiorizada na Amazônia, com novas discussões em torno das unidades de conservação e reservas indígenas que lá estão, ou mesmo a implantação do MATOPIBA, na área de tensão ecológica entre os domínios dos sertões secos e do cerrado. Na escala global, por outro lado, o Brasil assume cada vez mais responsabilidades ambientais além de intermediar o debate internacional voltado à conservação e contra mudanças climáticas.

No Rio Grande so Sul, estado em que se dá a pesquisa, a produção agropecuária é invariavelmente um dos pilares econômicos. A região da fronteira oeste é composta de pequenos municípios que tem na produção de soja, de arroz e pecuária as principais atividades. Apesar da riqueza gerada pela produção, a 
região da fronteira oeste, sudoeste e sul do estado concentram os piores índices de desenvolvimento humano do estado e do sul do Brasil.

Em relação ao aspecto ambiental é sabido que as atividades desenvolvidas geram uma utilização intensa do capital natural. A título de exemplo se tem o processo de arenização, típico da região e mesmo com anos de sua constatação e estudos, não é combatido nas raízes do problema. A água é outro elemento da paisagem que figura entre os problemas, pois os rios da região apresentam constantes problemas de assoreamento e contaminação por agrotóxicos.

Neste contexto socioambiental é que figuram as Bacias Hidrográficas do rio Butuí e Icamaquã (Figura 1). Com o intuito de gerar mais dados a respeito das atividades desenvolvidas e seus impactos, fornecendo informações para o debate no âmbito, dentre outros, da recente implantação do Comitê das respectivas Bacias Hidrográficas e ainda para o Zoneamento Ecológico Econômico, é que urge a demanda de compreender as interações da paisagem local.

A pesquisa busca, portanto, introduzir os estudos de caráter ambiental para as bacias em questão, e para tanto objetiva avaliar se a legislação ambiental voltada para APPs está sendo respeitada no que confere a vegetação ribeirinha. Para tanto utiliza o NDVI para comparação das áreas de APP delimitadas a partir de geoprocessamento. 


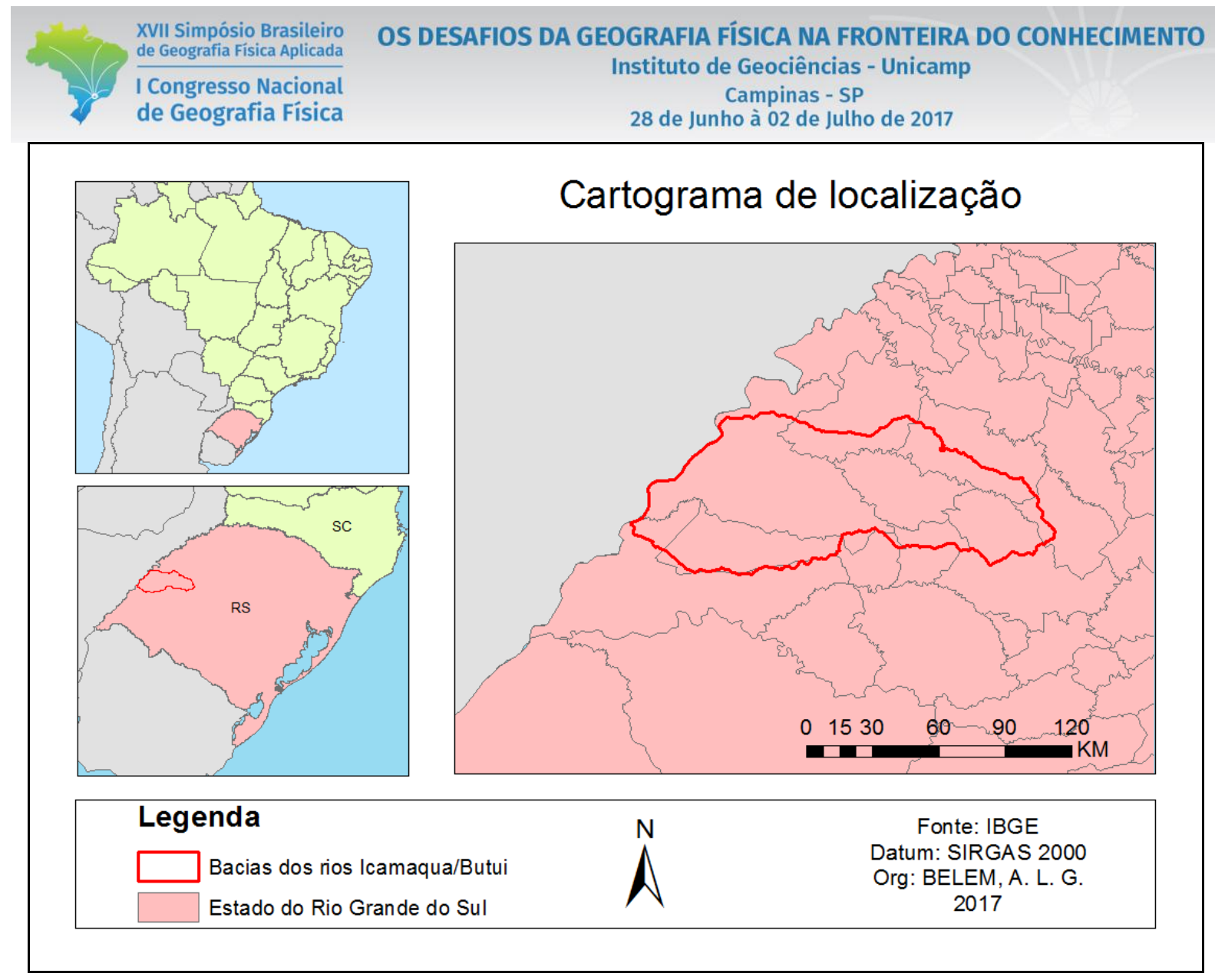

Figura 1 - Localização da área de estudos.

\section{Revisão Bibliográfica}

As bacias hidrográficas em questão abrangem áreas de nove municípios do estado do Rio Grande do Sul, sendo eles: São Borja, Itaqui, Maçambará, Unistalda, Santiago, Capão do Cipó, Bossoroca e Santo Antônio das Missões, e desaguam no rio Uruguai que faz fronteira com a Argentina. A quantidade de pessoas chega a $185 \mathrm{mil}$ com destaque para São Borja com 60mil e Santiago com 50mil pessoas aproximadamente. A vocação econômica é pautada no desenvolvimento do agronegócio principalmente na produção de pecuária, soja e arroz (IBGE, 2016).

Em relação às bacias analisadas, ambas fazem parte do mesmo Comitê de Gerenciamento, e por conta disso serão trabalhadas em conjunto. A bacia do rio Icamaquã é a maior, com 1305,9 km² chegando até a sexta ordem hierárquica e possui orientação SE-NO até desaguar no rio Uruguai. O rio Butuí, com $918 \mathrm{~km}^{2}$, corre de leste para oeste e chega até a quinta órdem, também desaguando no rio Uruguai. Aparecem ainda, dentro do mesmo comitê de gerenciamento, o Arrozio Santa Luzia e a Sanga da Estiva que desaguam diretamente no Uruguai e entremeiam os terços baixos dos Butuí e Icamaquã (ROBAÍNA 
et al., 2007). As bacias em questão são consideradas de risco de déficit hídrico pela Fundação Ambiental de Proteção Ambiental Henrique Luiz Roessler (FEPAM).

Em função das características climáticas e de relevo a paisagem da região possui áreas de banhados, constantemente drenados em favor da produção. Outra característica típica na paisagem da região é o represamento simples para criação de açudes voltados à irrigação.

Essa conformação da drenagem reflete a condição de relevo da região, ou seja, além da altitude em média $120 \mathrm{~m}$. Em relação a declividade há uma predominancia de inclinações inferiores a 5\%, sendo a maior parte considerado plano, o que equivale a $2 \%$ de inclinação. Assim, suas principais formas de relevo são as colinas e rampas. As formas mais acentuadas são os morrotes (ROBAÍNA et al., 2007). Trata-se de transição entre o planalto de Uruguaiana e o de Santo Ângelo, em que a fisionomia pouco muda (FEPAM, 2010).

Em relação à cobertura, a paisagem das bacias eram originalmente classificadas como pampa, ou campos sulinos (IBGE, 1992;.AB'SÁBER, 2003), é evidente a existência de banhados, campos com bosques de mata nativa, extenções das formações de floresta ombrófila mista e ainda matas de galeria, estas ultimas presentes em torno dos maiores cursos de água com presença constante de pau ferro (Astronium balansae). Em relação aos campos, tanto os campos sujos como os campos limpos são presentes nas áreas estudadas, trata-se de vegetação de estepe gramíneo lenhosa sem floresta de galeria, porém geralmente associados a áreas de preservação permanente como nascentes e margens de rios. A maior parte da ocupação do solo se dá com cultivo de soja, arroz, trigo, milho e pecuária.

\section{Procedimentos}

Foram utilizadas imagens do satélite Landsat 8, cuja resolução é de 30 metros. As imagens foram adiquiridas sem custo junto a divisão de geração de imagens do Instituto Nacional de Pesquisas Espaciais. Duas imagens foram utilizadas e datam dos dias 18 e 19 de janeiro de 2017.

A geração do NDVI contou com a utilização das bandas do vermelho e do infravermelho próximo, no caso específico das imagens utilizadas, tratam-se das bandas 4 e 5 respectivamente. Com as bandas selecionadas foi realizado um processamento digital nas imagens gerando o NDVI. Sendo a equação aplicada:

\section{NDVI $=$ IVP - V / IVP + V}

Onde: IVP: valor da reflectância da banda no infravermelho próximo. V: valor da reflectância da banda do vermelho. 
No âmbito da cartografia digital, foi utilizada a base de dados da FEPAM para ajustar a hidrográfia e delimitar as bacias. Uma vez delimitadas, organizou-se a tabela de atributos, conforme a largura dos rios para então mapear por meio de buffers as áreas de APP conforme a legislação 12.651/2012, o novo código florestal brasileiro. Obeserva-se que os modos de APP utilizados no primeiro momento da pesquisa foram o de rios, descartando momentaneamente o restante das possibilidades previstas em lei.

Ressalta-se que tanto a geração do NDVI como a cartografia digital realizada ocorreu no software Qgis 2.12 - Lyon, cuja licença é open souce. A análise dos dados ocorreu de modo qualitativo em função da diferença nos padrões de dados (vetor e raster), e principalmente em função da pesquisa estar em fase de desenvolvimento, cujos resultados preliminares são apresentados a seguir

\section{Resultados}

O NDVI foi gerado com facilidade demonstrando ser uma ferramenta prática, a figura 2 mostra o resultado do processo. A legenda do NDVI deve ser analisada considerando o comportamento dos diferentes usos do solo. A vegetação, em função da fotossíntese, apresenta uma maior reflectância que a água, ou que outras superfícies. Existem diferenças captadas entre os diferentes tipos de coberturas vegetais. Assim, a falsa cor aplicada nos resultados apresenta valores mais baixos para superfícies de água e solos expostos, ou cobertura vegetal com menor taxa de fotossíntese enquanto os valores mais altos representam formações vegetais arbóreas/arbustivas. Cabe ressaltar que a época do ano é um elemento essencial, pois, alguns cultivos são temporários e não permanentes. 


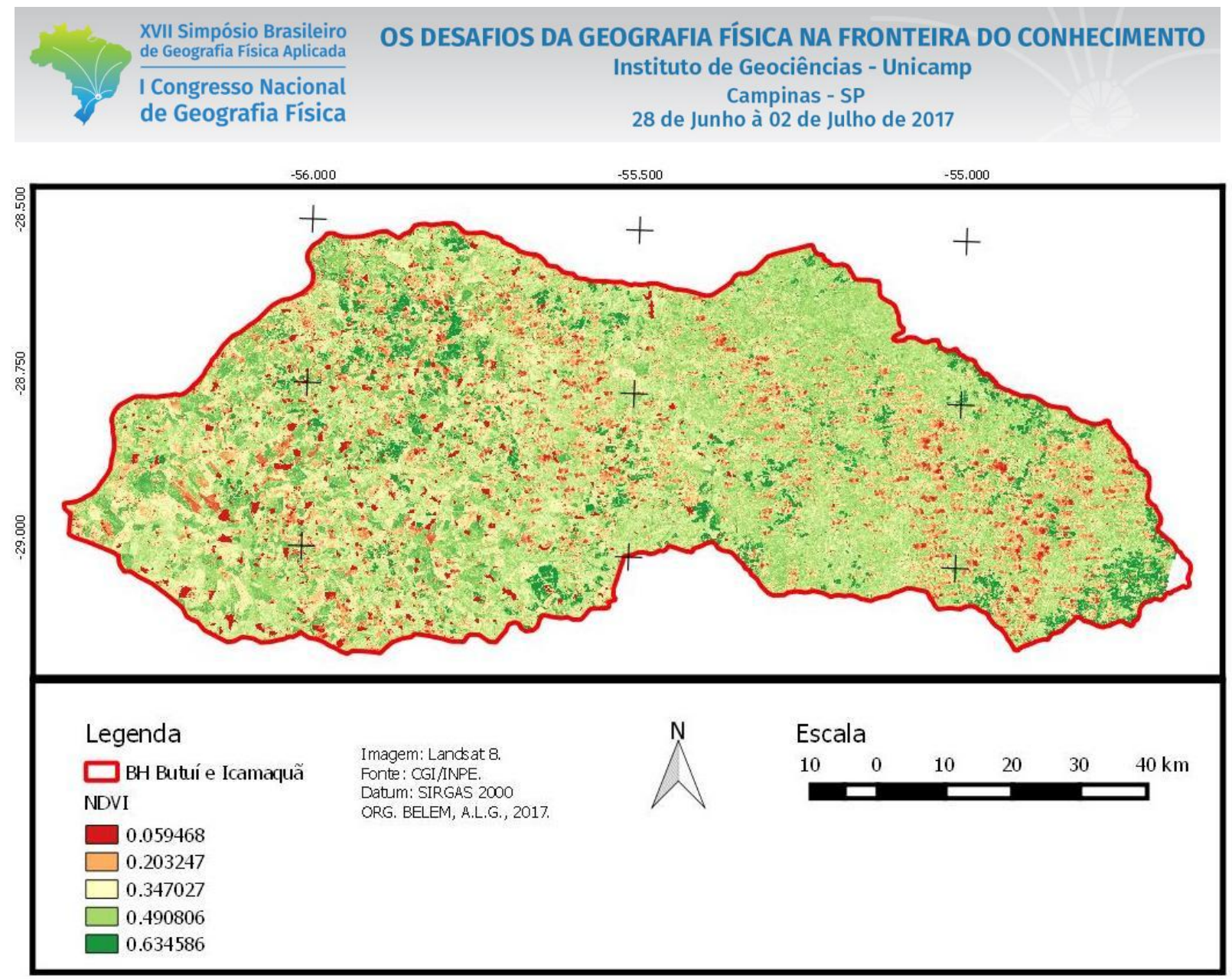

Figura 2 - Índice de Vegetação da Diferença Normalizada.

Conforme a figura 2, percebe-se que a área das bacias hidrográficas possuem muita presença de corpos hídricos concentrados, estes por sua vez são resultados, em grande parte, de alterações da paisagem original, pois conforme explica Robaína et al (2007) as áreas úmidas (banhados) são uma condição natural da paisagem, entretanto sua extensão é maior, em geral, do que as inúmeras pequenas e bem definidas áreas em vermelho no mapa. A verificação de campo comprova esse processo de criação de açudes e desvio nos cursos da água.

Outros dois padrões são facilmente identificados: o primeiro ao noroeste (figura 2) evidência uma vegetação mais fotossintetizante, composta por resquícios e capões florestais remanescentes. O terceiro padrão pode ser verificado no terço médio das bacias ao norte, campos em verde claro e amarelo compõem um mosáico de cultivos e pequenas APPs.

As APPs delimitadas focaram nos principais rios da região sendo ao sudoeste do mapa o Butuí e ao norte correndo de sudoeste para noroeste, o Icamaquã. Aparece ainda no limite oeste das bacias o rio Uruguai, o único que se enquadrou no limite de APP de 500m. Os rios Butuí e Icamaquã e seus principais afluentes se enquadraram nas APPs de $100 \mathrm{~m}$. Por fim os principais riachos e córregos entraram na 
categoria de $30 \mathrm{~m}$. Sendo que os pequenos cursos de água menores, muitas vezes intermitentes não foram considerados em função da resolução de 30 metros da imagem.

A comparação entre o NDVI e as faixas de APP, objetivo central do estudo, trouxe algumas dificuldades. Em função de a região apresentar naturalmente áreas alagadíças, muitas áreas em vermelho (figura 2) resultaram em interpretação dúbia, impossibilitando sua definição, ou seja, seriam áreas impactadas ou de cobertura original? A resolução da imagem possibilitou o trabalho em escala 1:60.000 na comparação, e, em tal escala foi possível identificar que a vegetação rasteira de campos naturais e pastagens plantadas, ou cultivos em início de desenvolvimento apresentam reflectância muito parecida. Assim, o que as diferenciou foi o padrão espacial, a matriz de uso do solo. Porém, não é possível ter certeza em todos os casos, comprometendo os resultados.

A figura 3 apresenta alguns dos padrões mais encontrados e um exemplo de área urbana. O quadro superior direito mostra como se dão alguns conflitos em áreas de APPs de 100m. Diferentes cultivos, com respostas expectrais diferentes, invadem os polígonos em preto (APPs) mostrando um abuso que ultrapassa os limites legais. Uma grande mancha vermelha é um banhado natural e o seu entorno deveria ser protegido, o que não acontece. Os açudes são outra constante, inclusive alterando o curso de um afluente, o que é recorrente.

O quadro superior esquerdo, mostra uma dinâmica de excessão para a região. A cidade de São Borja, entra na área de APP do rio Uruguai. Como a frequência de áreas urbanas é muito baixa na região, torna-se uma excessão, mas o desrespeito à legislação também ocorre nesse caso.

Observando o padrão da terceira imagem (inferior direita), já no rio Icamaquã, tem-se uma ocupação muito intensa da terra, todavia mesmo para os afluentes pequenos da margem esquerda aparentam estar com suas APPs respeitadas. O que indica, isso para o rio principal, é a tonalidade diferente tanto em relação a porção norte quanto à porção sul. Nesse sentido o terço inferior do rio Icamaquã apresenta uma condição boa de modo geral, assim também ocorre no rio Butuí.

O ultimo quadro (inferior esquerdo) mostra as cabeceiras, quanto a elas, tanto as nascentes quanto os cursos de rios são alterados. Uma nascente em vermelho intenso é o reflexo de um açude implantado, enquando que dois pequenos rios no centro e esquerda da imagem aparecem interrompidos, pois seus cursos não seguem naturalmente. A área é totalmente ocupada para produção e os recursos naturais são aplicados a esta atividade. As cabeceiras dos dois rios seguem o mesmo padrão. 


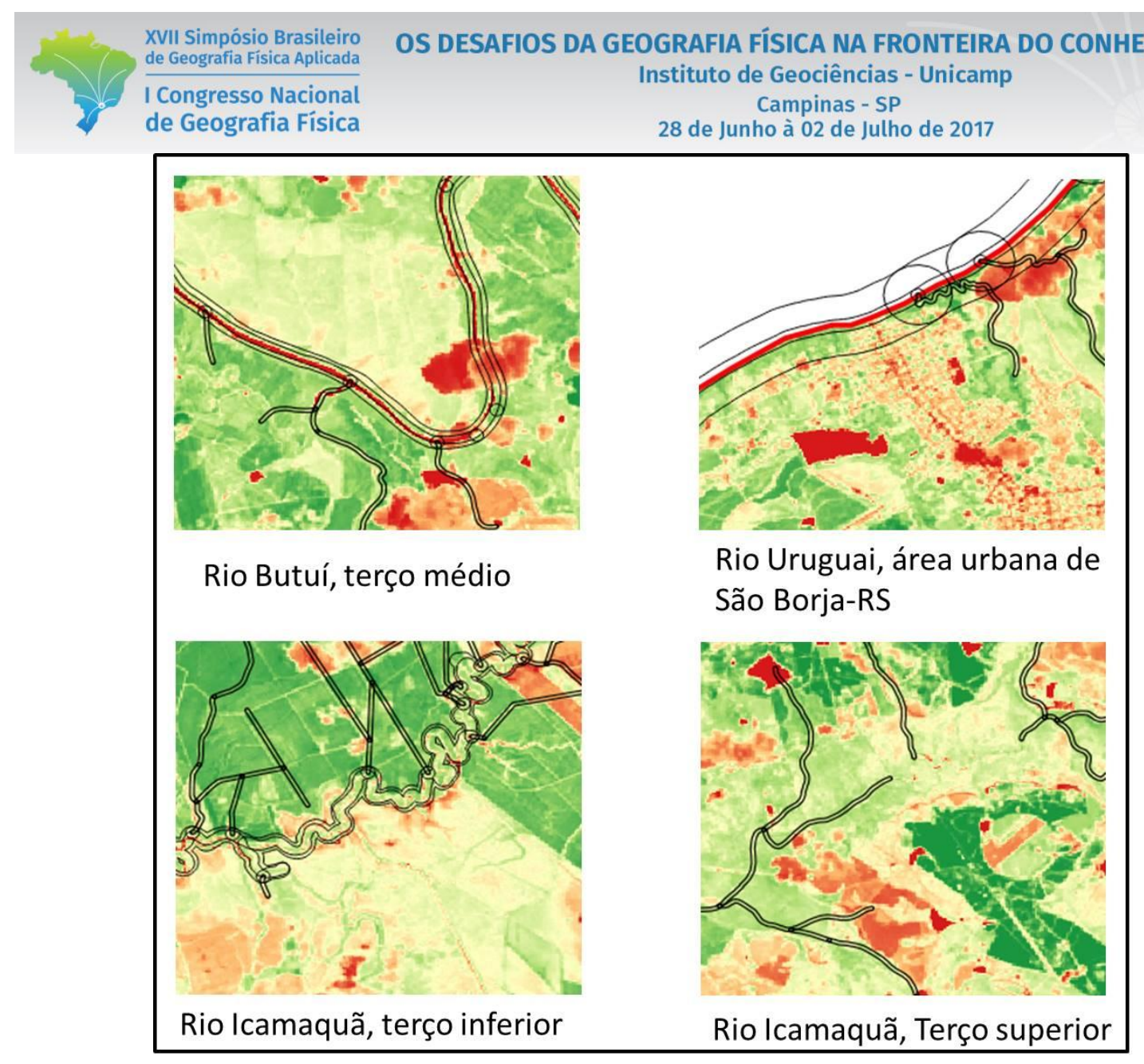

Figura 3 - Padrões espaciais de conflitos e conservação de APP.

\section{Conclusão}

O trabalho não é conclusivo ao analisar o estado de conservação das áreas de preservação permanente no que confere à área estudada, o aprofundamento nas pesquisas, bem como a sequência temporal é necessária para caracterizar com maior propriedade os resultados encontrados. A quantificação dos dados é outro elemento que evidenciaria a proporção de áreas respeitadas ou não podendo apresentar maior clareza nas conclusões.

De modo geral, as bacias tem um melhor grau de conservação de APP quando se aproximam de suas fozes. Nas cabeceiras há um intenso problema em função, inclusive, da facilidade que o relevo proporciona. Verifica-se ainda, pelo NDVI que há muitas áreas de açudes e mesmo áreas alagadas naturais, o que confunde a utilização do procedimento para mapear as APPs.

Em relação ao procedimento adotado, fica clara a necessidade de maior desenvolvimento de pesquisas na área do bioma pampa juntamente com vistas aos recursos naturais, pois foi constatada a pouca referência a estudos que não fossem voltados para a produção vegetal o que se configurou um 
problema para a identificação dos valores de reflectância específicos das formações vegetais herbáceas nativas da região, sendo um método voltado aos padrões espaciais utilizados.

\section{Bibliografia}

AB’SÁBER, A. N. Os Domínios de Natureza no Brasil. São Paulo: Ateliê Editoriais, 2003.

BRASIL. Lei 12.651, de 25 de maio de2012. Disponível em: planalto.gov.br. Acesso 26/03/2017.

FEPAM. Diretrizes da Silvicultura por Unidade de Paisagem e Bacia Hidrográfica. Porto Alegre: Secretaria Estadual de Meio Ambiente, 2010.

IBGE. Censo Agropecuário. Brasília: Governo do Brasil. 2016.

IBGE. Manual Tecnico da Vegetacao Brasileira. 1. ed. Rio de Janeiro: Governo do Brasil, 1992.

ROBAÍNA, L. E. DE S. et al. Atlas Geoambiental De São Borja-RS. 1. ed. Santa Maria: LAGEOLAM, 2007. 